\title{
An Analysis of Adolescent and Parental Views on the Psychoeducation Program for Coping with Aggressive Behaviors
}

\author{
Suat Kılıçarslan ${ }^{1}$, Meral Atıc1 ${ }^{2}$ \\ ${ }^{1}$ Department of Psychological Counselling and Guidence, Ömer Halisdemir University, Niğde, Turkey \\ ${ }^{2}$ Department of Psychological Counselling and Guidence, Çukurova University, Adana, Turkey \\ Correspondence: Suat Kılıçarslan, Department of Psychological Counselling and Guidence, Ömer Halisdemir \\ University, Niğde, Turkey.
}

Received: March 29, 2017

doi:10.11114/jets.v5i6.2307
Accepted: May 2, 2017

Online Published: May 3, 2017

URL: https://doi.org/10.11114/jets.v5i6.2307

\begin{abstract}
The aim of this study is to investigate the views of parents and adolescents who participated in psychoeducation programs for coping with adolescent aggressive behaviors. Parents who participated in the study were provided with a program known as the "Non-Violent Resistance Parent Program," and adolescents participated in the "Coping with Violence and Aggression Psychoeducation Program." Both programs were designed based on systemic family therapy theories. The views of participating parents and adolescents were obtained through a semi-structured interview form developed by the researchers. The interviews were subsequently analyzed using content analysis methods.

After the programs' culmination, participants stated that the programs reduced aggressive behaviors seen in adolescents, improved parents' parenting skills and family relationships, and significantly decreased parental inefficacy and stress levels. Results of the analysis of qualitative data obtained from interviews indicated that adolescents and parents generally benefitted from the programs, experienced positive emotions in the process, and gained significant awareness about their interaction styles and those of other family members. It was stated that conducting the two programs simultaneously was very helpful, for the participants reportedly experienced closer familial relationships as well as changes in their approach to problems. On the other hand, the participants noted that the program had some weaknesses: they sometimes had difficulty in expressing themselves and restoring family relationships in the process; fathers' absence in the program was challenging for them; and the process did not have much contribution to spousal relationships. Based on these results, it is recommended that these programs should be conducted with parental cooperation in all institutions providing service to adolescents, particularly in schools. Both the improvement of parenting skills and the establishment of constructive and warm familial ties have the potential for reducing violent and aggressive behaviors in adolescents.
\end{abstract}

Keywords: violence, aggressiveness, coping with violence and aggression program, non-violent resistance program, family relationships

\section{Introduction}

In recent years, there has been a noticeable rise in violent and aggressive behaviors in Turkey and throughout the world. An analysis of the violent behaviors observed during childhood and adolescent periods shows that some genetic, biological, social, cultural, and emotional factors, combined with family structure and unhealthy family relationships and interaction styles within family, play a significant role. In this process, parental and adolescent communication habits could be fostered in a better way and the relationships might be reconstructed.

Various views exist on the subject of violence, which is one of the most common problems that occurs during adolescence, a critical period that every individual experiences. Freedman, Sears and Carlsmith (1993) define violence as "any kind of behavior that aims to hurt others."

Research on families demonstrates the importance of effective, healthy parent and adolescent relationships for the mental health and the future of society (Cerit, 2007). Studies on the relationships of children with behavioral problems with their parents indicate that this process is very problematic (Polowczyk et al., 2000). This vicious cycle can be broken by maintaining healthy relationship habits between parents and adolescents. At this point, parent programs, based on the 
positive effects of the program on rearranging parent and adolescent relationships, are expected to affect behavior styles of parents towards their children and thus decrease their behavioral problems.

With the effects of parental attitudes on the development of children's behavioral problems in mind, it becomes necessary to intervene in children's behavioral problems by shaping both parental and child behaviors (Arkan and Üstün, 2009). Violence and aggression in this study are not only viewed as a problem experienced by an individual, but also as a social and cultural structure problem that affects the entire family.

Review of the related literature indicates that there are various programs designed to cope with violence and aggression among adolescents in Turkey and across the globe. Some of these programs, at the individual level, include school-based programs such as social development programs, life skills education, conflict resolution, skills education, anger management, problem solving skills education, communication skills education, empathy skills, and peer education. Numerous meta-analytic studies in the literature report that prevention and intervention programs for students and families are effective methods in decreasing violence and aggression behaviors and yield positive outcomes for children and adolescents who have violent behaviors (Wilson, Gottfredson and Najaka, 2001; McCart, Prienter, Davies and Azen, 2006; Scheckner, Rollin, Kaiser-Ulrey and Wagner, 2002; Sukhodolsky, Kassinove and Gorman, 2004; Wilson and Mark, 2005; Wilson and Mark, 2007; Şahin \& Kalburan, 2009; Bacıŏlu, 2014). Studies in Turkey generally focused on helping adolescents and parents to control emotions and behaviors and to increase empathy, anger management, and conflict resolution skills. In effect, there is a lack of studies viewing parent and adolescents as a whole. There is thus a need for studies that investigate family processes such as family relationships and interaction styles together.

The purpose of the education programs used in this study is to give structure to family life and to decrease problematic violent and aggressive adolescent behaviors demonstrated at home or in school by changing parent-adolescent interactions and teaching individuals skills about such topics as anger, tension, and stress and conflict management issues. Another goal is to prevent the behavioral problems in adolescents from arising by preventing negative attitudes and behaviors of parents toward each other and toward their children.

The fact that violence and aggressive behaviors in adolescents have a multiple etiology might indicate that comprehensive studies involving school, family, and society all together are required for effective prevention programs. The creation of education programs for parents are quite important for Turkey, particularly when it comes to the violence and aggression behaviors and to the dissemination of these programs. While related literature indicates that studies on this issue have generally been conducted in other countries, more studies need to be conducted in Turkey. Since this study is the first parent group study based on a systemic approach in Turkey, it is expected to contribute to the field, prevent violent and aggressive behaviors in adolescents, and therefore contribute positively to familial relationships.

\subsection{Aim of the Study}

This study investigates parental and adolescent views on the effects of the programs provided to participants on aggressive behaviors seen in adolescents and in familial relationships. The programs are entitled "Coping with Violence and Aggressive Behaviors" (henceforth abbreviated as CVAB), which aims to decrease violent and aggressive behaviors among adolescents, and the "Non-Violent Resistance" parent program (henceforth abbreviated as NVR), which was formed for parents whose children demonstrate violent and aggressive behaviors.

The study explores participant views on the outcomes of the experiential procedures through the qualitative data obtained:

- What are the opinions of experiential group parents on the effects of the NVR parent program provided to parents and the CVAP program provided to their children?

- What are the opinions of experiential group adolescents on the effects of the CVAP program provided to them and the NVR parent program provided to their parents?

\section{Method}

\subsection{Participants}

After the programs were completed, in-depth interviews were conducted with parents and adolescents who participated in the psychoeducation groups regarding their experience and attainments in order to investigate the effects of the programs applied in the study. The participants were volunteer students who were enrolled in a secondary school in the 2014-2015 educational year and whose Aggression Scale (AS) scores were one standard deviation above the mean score, as well as volunteer $9^{\text {th }}, 10^{\text {th }}$, and $11^{\text {th }}$ grade students and their parents. $12^{\text {th }}$ grade students were not involved in the study since they were approaching graduation, and most were preparing for the university exam. Hence, qualitative data were obtained from 34 participants (17 students and 17 parents), who participated in the psychoeducation experiential groups. 


\subsection{Data Collection Tools and Data Collection}

Qualitative data of the study were obtained from the students and parents who were provided with psychoeducation programs. The participants' personal successes and feedback were obtained through interviews using a "semi-structured interview form" developed by the researchers. One of the mothers was not interviewed because she was diagnosed with cancer. As her illness progressed, she had to continue her treatment at the hospital.

The interviews based on a specific form enabled researchers to obtain both systematic and comparable information from different individuals. While formulating the interview questions, researchers ensured that: special attention would be given to make the questions easy, thereby encouraging the interviewee to speak; the questions be focused; and that they move from specific to general questions (Yıldırım and Şimşek, 2006). Therefore, by asking the preparatory questions first, and focused and specific and general questions later, the researcher asked the parents and adolescents seven questions. They were asked to reflect upon the following: a) emotions experienced in the process; b) newly acquired skills and attainments; c) self-awareness of the participants and their families; d) effects of the program on the participants' relationships with their family; e) views on the effects of the program administered simultaneously on other family members; f) strengths and weaknesses of the program; and g) thoughts on any challenges experienced in the process and any suggestions.

\subsection{The Coping with Violence and Aggression Psychoeducation (CVAP) Program}

The group work provided to adolescents was designed in a way to support the NVR applied to parents. Aims of the program include being less vulnerable to violence, empowering self-control, enhancing perception skills regarding one's own behaviours, developing empathy for the victim, improving communication and social skills, increasing self-respect, and raising awareness about the individual's behaviours and family interaction network. It was based on a systemic psychotherapy approach. Instead of attitudes and behaviors such as verbal and physical aggression, hostility and hate, the program sought to teach adolescents to cope with any tension they experience in the face of conflicts by improving their communication and social skills such as constructive conflict resolution, as well as communication and social skills. On the other hand, in cases where anxiety and anger were experienced, by benefitting from cyclical questions about the effects of intra-family interactions on behaviors and the effects of behaviors on intra-family interactions, the program aimed to contribute to awareness of the demonstrated behaviors and therefore strengthen their coping mechanisms.

The CVAP program included skill development activities with a focus on preventing violent behaviors among adolescents. This study focuses on students who draw attention with violent behaviors or high aggression levels at home and school. It was conducted with a group of 17 students aged between 15 and 18. Group sessions took 90 minutes on the average and were conducted on weekly basis.

The content of the CVAP program was constructed this way: $1^{\text {st }}$ week: Meeting, Introduction, Aggression, What are Aggressive Behaviors?; $2^{\text {nd }}$ week: What is Conflict? What Are its Sources and Effects?; $3^{\text {rd }}$ week: Noticing and Expressing Emotions; $4^{\text {th }}$ week: Effective Listening Skills, Communication Skills; $5^{\text {th }}$ week: Empathy Skills; $6^{\text {th }}$ Week: Family Interaction; $7^{\text {th }}$ Week: Anger and Anger Management; $8^{\text {th }}$ Week: Relaxation Exercises; $9^{\text {th }}$ Week: Conflict Resolution Skills; and $10^{\text {th }}$ week: Closure, Evaluation. The topics that are covered in a process-driven way included the following issues: Development of one's own Violent Behaviour, Self and External Evaluation of one's own Violent Behaviour, Focusing on one's own Needs and Emotions, Current Violent Behaviours of the Group Members, Perspective and Emotions of the Victim, Results of Violence, Alternative Communication and Action Strategies, Effects of Family Experiences and Emotions on Anxiety and Violence, and Negative Effects of Violence on Family Interactions. Main Methods and Techniques used in the CVAP program: Act-out activities where adolescents took various roles and thereby realized different aspects of their behaviours. Administration of the scales that enabled them to evaluate themselves and others. Administration of "Result-benefit Analysis" to evaluate the results of the adolescents' behaviours. Intervention to crisis: An adolescent's current conflict is discussed in the group, and beneficial solution opportunities are analysed.

Administration of family tree (Genogram) and family constellation techniques that aimed to explore the effects of family interaction network on individuals' attitudes and behaviours and the effects of individual attitudes and behaviours on family structure and interactions, and hot chair technique specifically designed to help adolescents face their own violent behaviours.

\subsection{Non-violent Resistance Program (NVR)}

The experiential group, consisting of parents of students with violent and aggressive behaviors, was administered the NVR parent program (Elizabeth and Elizabeth, 2010). The program comprises individual parent interviews, with ten sessions of skills education: 1. Tension Increase; 2. Parent existence at home; 3. Baskets; 4. Supporters and Support systems; 5. Announcement technique; 6. Parent Values, Announcement, Acts of Reconciliation; 7. Active 
Resistance/Opposition; 8. Sit-in, 9; Parent Existence out of home; and 10. Summary and Certification, and supplementary three sessions (1: Announcement/Proclamation, 2. Sit-in, 3. Self-care). In addition to the program, one extra session, which included family tree (Genogram) and Family Constellation techniques, was conducted for the purpose of exploring the effects of family interaction networks on individuals' attitudes and behaviors, and the effects of individual attitudes and behaviors on family structure and interactions. In addition to the NVR program, role playing activities, and watching videos, the parents were provided with support via telephone throughout the program. Those who needed additional support were paid home visits.

The NVR program was designed with the purpose of helping parents cope with children's disciplinary problems such as activities that may cause to harm themselves, skipping school, and other acute discipline problems (Omer, 2011, 2004). The program aims particularly to help helpless parents who feel anxious about their children to gain their parenting back by teaching them to oppose violent and self-destructive behaviors in an effective way, without provoking others or giving up. Although the treatment is applied to parents, the main viewpoint centers on both children and parents (Omer, Steinmetz, Carthy and Schlippe, 2013).

NVR has been developed as a socio-political strategy to resist violence (Sharp, 1973; Lavi-Levavi, Shachar, Omer, 2013). Adapting NVR to family context was based on the observations that indicated parents' feelings of desperation and anger (Bugental, Blue and Cruzcoza, 1989). Defenders of the NVR treatment program hypothesize that the program would help them to effectively resist children's violent and self-destructive behaviours in a way that would not increase violence or tension. NVR is assumed to enable parents to build a reassuring and stable relationship for their children (Omer, Steinmetz, Carthy and Schlippe, 2013). By learning how to control themselves and how to resist their children's behaviours persistently, but not in a violence-increasing way, parents could be protective and keep their children in balance in dangerous situations.

Three features used in parent education form base for the socio-political principles of NVR: a) Presence, or direct personal involvement, which means "We are your parents and will remain your parents. You cannot get rid of us, leave us or put us away". b. Self-control (instead of having control over the child) or taking a non-violent position, which means "We cannot control you (child), but we can control ourselves. We will do our duty and will not raise the tension", and c. Support, which means that parents learn to speak and act using first person plural (we) instead of "You will do what I tell" Parents develop a transparent attitude in this process. This attitude is a strong antidote for the compelling and haphazard atmosphere that develops under confidentiality conditions. For strategies and tactics, special techniques developed by Mahatma Gandhi and Martin Luther King, Jr. were taken as models. Parental autonomy notion in NVR should be built upon a determinant presence that does not increase tension and that enables parent-child relationship combined with discipline and safety issues. Various approaches point to relational and disciplining (limiting) aspects of parenting. However, these two fields generally represent different aspects and are even seen as different phases of the treatment that include "relational phase" (parents are educated for developing positive communication with the child) and "empowerment phase" (parents react to the child's positive or negative behaviours). Fundamental attitude in NVR is quite different: it develops a stable relationship framework in establishing parents' presence, self-control and support networks and show same consistent reaction to negative behaviours. Parental connection and parental empowerment develop together (Lavi-Levavi, Shachar, Omer, 2013).

\subsection{Data Analysis}

Interviews conducted with the group members who participated in the experiential study were recorded using a voice recorder after participant consent was obtained. Data from the voice recordings were transcribed, and the texts were then analyzed using content analysis methods. The purpose of content analysis is to reach concepts and relationships through the data obtained. The process includes bringing similar data together in the framework of some concepts and themes, and then organizing and interpreting the data in a comprehensible way (Yıldırım and Şimşek, 2013).

The data obtained from the interviews and transcribed in the framework of an evaluation form were first read by a researcher. Furman, Langer and Taylor (2010) report that repeating the coding process after some time lend credibility to the qualitative data analysis. Therefore, the researchers waited for one week following the first coding procedure, reviewed the previous coding, and made some revisions and new coding. Hence, special attention was paid to make the coding coherent and accurate with the data. Then, themes were identified with the codes from data obtained from adolescents and parents. The findings were presented through the tables showing codes/concepts belonging to the themes and theme codes, and the participants' expressions were presented using their direct quotations. Expert opinions were received for the codes and the themes obtained. Validity and reliability of the data were enhanced by taking into consideration the consistency between the codes conducted by the researcher and the expert, as well as the principles of time invariance and consistency between the independent observers. 


\section{Findings}

This section presents findings in relation to the participants' views on the CVAP program provided to the adolescents and "Non-Violent Resistance" program provided to the parents. The findings were presented by directly quoting the participants' expressions during the interviews; and parents' statements were represented with "P" and those of adolescents with "A" in order to preserve anonymity. The participants were numbered from 1 to 17 , according to the order of the transcriptions.

\section{Views of the Parents and Adolescents in the Experiential Group in relation to the Programs}

This study investigates participants' views on the CVAP program provided to the adolescents, and the NVP program provided to the parents. Data obtained from the interviews were analyzed using content analysis techniques. Qualitative data obtained from the adolescents and parents were analyzed separately, but the findings were presented in the same table. Table 1 lists the emotions expressed by adolescents and parents in the process.

Table 1. Emotions Expressed by Adolescents and Parents during the Process

\begin{tabular}{|c|c|c|c|}
\hline \multicolumn{4}{|c|}{ Emotions Experienced in the Process } \\
\hline Parents' Emotions & $\mathbf{f}$ & Adolescents' Emotions & $\mathbf{f}$ \\
\hline Pleasant Emotions & & Pleasant Emotions & \\
\hline Calm & 16 & Calm & 33 \\
\hline Self-confidence & 6 & Happiness & 7 \\
\hline Contentment & 6 & Comfort & 5 \\
\hline Pleasure & 4 & Feeling valued & 5 \\
\hline Feeling well & 3 & Self-confidence & 3 \\
\hline Relief & 3 & Having fun & 3 \\
\hline Happiness & 3 & Support & 2 \\
\hline Surprise & 2 & Feeling well & 2 \\
\hline Approval & 1 & Being Free & 2 \\
\hline Satisfaction & 1 & Confidence & 1 \\
\hline Unpleasant Emotions & & Feeling understood & 1 \\
\hline Tension & 1 & Important & 1 \\
\hline Uneasiness & 1 & Patience & 1 \\
\hline Anxiety & 1 & Respect & 1 \\
\hline Guilt & 1 & Relaxation & 1 \\
\hline Increased strength & 1 & Unpleasant Emotions & \\
\hline Dread & 1 & Embarrassment & 1 \\
\hline Fear & 1 & Offence & 1 \\
\hline Nervousness & 1 & Excitement & 1 \\
\hline & & Anxiety & 1 \\
\hline & & Neglect & 1 \\
\hline
\end{tabular}

An analysis of Table 1 indicates that adolescents and parents generally experienced positive emotions such as calm, comfort, self-confidence, feeling valued, happiness, as well as support, contentment, and having fun. Unpleasant feelings, including tension, anxiousness, uneasiness and dread were experienced less often.

The following quotes reflect emotions experienced by the participants during the group process:

"It was good both for me and for my child. My emotional wellbeing was also really bad when I came here. I was feeling too bad. It was good for me, too. I gathered myself up. I began to feel more confident I felt stronger". (P-4)

"It was like medicine for me, like a painkiller or tranquilizer. It was really good because I had been feeling helpless, I did not know what to do, and I did not know how to approach that situation. Learning the approaches really helped me". (P-5).

"Before the training my family did not use to understand me; now they do. In fact, they can even show empathy. I mean that they make me feel that they understand me. I am happy because they understand me and know my feelings". $(A-3)$.

"It was good to be part of this group. Knowing that my friends also experience similar problems that they could also experience them surprised me a little, I mean, I felt different. Expressing their emotions and finding that their emotions were similar to mine was surprising" $(A-8)$.

Table 2 presents findings on adolescents and the skills and attainments they gained in the process. 
Table 2. Newly Acquired Skills and Attainments

\begin{tabular}{|c|c|c|c|}
\hline \multicolumn{4}{|c|}{ Newly Acquired Skills and Attainments } \\
\hline Adolescent Views & & Parental Views & \\
\hline Communication Skills & f & Communication Skills & f \\
\hline Communication and self-expression skills & 24 & Communication and self-expression skills & 12 \\
\hline Understanding others & & Understanding others, Learning from & \\
\hline Empathy skills & 20 & others, and sharing & \\
\hline Effective listening skills & 9 & Seeing different viewpoints & 9 \\
\hline Risk taking/assertiveness & 1 & Developing new friendships & 4 \\
\hline Improvement in friendships & 1 & Learning different information & 3 \\
\hline Conflict Resolution and Anger Management & & Knowing and understanding people & 1 \\
\hline Anger management & 11 & Learning to communicate with children & 1 \\
\hline Thoughtfulness & 5 & Helping others & 1 \\
\hline Discussing less & 3 & Conflict Resolution and Anger Management & \\
\hline Giving a break & 1 & Anger management & 2 \\
\hline Decrease in lash out & 1 & Problem solving & 1 \\
\hline Conflict and Problem Solving Skills & & Not showing reactions, (remaining neutral) & 1 \\
\hline Helping others & 4 & Being patient & 1 \\
\hline Positive thinking & 3 & Relaxation Skills & \\
\hline Problem solving skills & 3 & Relaxation exercises & 3 \\
\hline Ignoring problems & 1 & & \\
\hline Checking one's limits & 1 & & \\
\hline Resisting without violence & 1 & & \\
\hline Relaxation skills & & & \\
\hline Relaxation exercises & 8 & & \\
\hline Ability to calm down & 5 & & \\
\hline
\end{tabular}

An analysis of Table 2 shows that under communication skills, adolescents improved themselves in areas such as communication and self-expression, as well as understanding others (empathy, effective listening skills and risk taking). Under the anger management category, adolescents improved their anger management, conflict and problem solving skills, and relaxation skills. As for parents, they improved themselves in communication and self-expression, understanding others, learning from others and sharing, seeing different points of views, developing new friendships, conflict resolutions, anger management and relaxation skills.

Below are some examples of participant statements about their newly acquired skills and attainments:

"About myself... I think I have improved. I think I am now more comfortable. It is so hard to set aside time for oneself; but I see that one can do that if one really wants. I have realized that if I want I can do something for myself and my family" (P-12).

"I have learned many things. I did not expect this much participation. I saw that everybody needed it, not just me. I mean felt that I was not alone. I realized how I should communicate with my children. I understood how to stay calm in case of a problem (P-16).

"Generally I have begun to understand people around me...How and why they behave in a specific way. I have begun to act accordingly. I now distance myself from people with problems. I mean, I used to attack immediately when someone came at me. Now, I pause momentarily and then try to speak" (A-1).

"First of all, the relaxation exercises have really worked. I can express myself without fighting with, for example, my brother. This will prevent constant troubles. I mean, I have learned that instead of reacting immediately, I should wait for a while and give a break so that people can calm down. I believe I have calmed down" (A-8).

Table 3 presents findings on the effects of the training provided to other family members. 
Table 3. Views on the Effects of the Program on Family Members

\begin{tabular}{|c|c|c|c|}
\hline \multicolumn{4}{|c|}{ Effects of the Program on Family Members } \\
\hline Parental Views & $\mathbf{f}$ & Adolescent Views & $\mathbf{f}$ \\
\hline Improvement in Intra Family Communication and & & Improvement & \\
\hline Relationships & \multicolumn{3}{|c|}{ Communication and Relationships } \\
\hline Increase in intra family communication & 12 & Increase in sibling relationships & 13 \\
\hline Improvement in sibling relationships & 4 & Increased family ties & 11 \\
\hline Spending time together & 3 & Increase in communication & 7 \\
\hline Valuing family members & 2 & Listening & 6 \\
\hline Respect & 2 & Empathy & 4 \\
\hline Listening Skills & 1 & Decrease in the tone of voice & 3 \\
\hline No quarreling & 1 & Expressing feelings of love & 3 \\
\hline Kindness & 1 & Being kind and soft & 3 \\
\hline Expressing themselves & 1 & Expressing themselves & 2 \\
\hline Decrease in the tone of voice & 1 & Increased discussions & 2 \\
\hline Understanding one another & 1 & Being understanding & 1 \\
\hline Increase in spousal communication & 1 & Increase in familial relationships & 1 \\
\hline Social Skills & & Decrease in Problems & 1 \\
\hline Apologizing & 2 & Social Skills & \\
\hline Accepting mistakes & 2 & Anger Management & 11 \\
\hline Being sociable & 1 & Conflict and problem resolution & 3 \\
\hline Avoiding violence & 1 & Knowing one another & 1 \\
\hline Emotional Awareness/Pleasant Emotions & & Emotional Awareness/Pleasant Emotions & \\
\hline Calm & 14 & Being calm & 16 \\
\hline Hope & 2 & Feeing understood & 11 \\
\hline Self-confidence & 1 & Decrease in tension & 3 \\
\hline Happiness & 1 & Sharing emotions & 1 \\
\hline Benefiting from the training/behavioral change & & Democratic Attitude & \\
\hline Behavioral change & 9 & Increase in interest & 6 \\
\hline \multirow[t]{4}{*}{ Applying what has been learned } & 4 & Decrease in pressure & 3 \\
\hline & & Guiding & 1 \\
\hline & & Flexibility in strict rules & 1 \\
\hline & & Increased responsiveness & 1 \\
\hline
\end{tabular}

An analysis of Table 3 indicates that parents think their children experienced pleasant emotions in the psychoeducation program provided to them. For example, they reported increased calm and feelings of hope. In particular, intra family communication and relationships improved, sibling relationships improved, there has been an increase in such behaviors as spending time together and family members' valuing and respecting each other, their social skills increased, the child's reactional behaviors decreased, and they applied what was learned. Adolescents, meanwhile, reported observed improvement in intra family communication and relationships such as closer family ties; increase in sibling relationships and listening and empathy; experienced emotional awareness and pleasant emotions such as parents' being calm and comfortable and decrease in tension; and changes such as adopting a democratic attitude.

These changes are reflected in the following parent and adolescent statements;

"I have become calmer, and so has my child. These days he is calm, I mean that he is becoming a better listener. His father is similar, our communication is better now. We can solve some problems by talking, so it has contributed in that sense" $(P-4)$.

"These two programs have been useful for both of us. I have observed some changes in my son. He did not used to spend time with us. He used to be in his room, on his tablet or telephone. He was not sociable. Now he wants to go out. He has begun to socialize. This case has improved family relationships" (P-6).

"I have observed some changes, specifically with my mother, who has begun to understand me. Now she understands what I feel and think because I am young. She does not interfere with me anymore. Yes, she has become more sensitive. We do not experience conflicts anymore; if we do, we can solve them quickly" (A-3).

"My dad did not participate in the training. There have been very important changes in my mother. Her behaviors have changed a lot. She used to get angry quickly, now she has become more sensitive. Now, at least she is listening. We did not use to be able to say "I love you" before. (A-17).

Tables 4 and 5 demonstrate adolescent and parental views on the psychoeducation group process under the themes of weaknesses/negative aspects and strengths/positive aspects. 
Table 4. Parental and Adolescent Awareness of the Weak and Negative Sides of Their Life

\begin{tabular}{|c|c|c|c|}
\hline \multicolumn{4}{|c|}{ Parents' and Adolescents' Awareness about the Weak and Negative Sides of Their Life } \\
\hline Parent views & f & Adolescent Views & \multirow[t]{2}{*}{$\mathbf{f}$} \\
\hline Weaknesses/Negative Sides & & Weaknesses/Negative Sides & \\
\hline Family related & \multicolumn{3}{|c|}{ Anger Management, Conflict and Problem } \\
\hline Distance from one's family & 6 & Solving & \\
\hline Challenging root family relationships & 4 & Lashing out & 9 \\
\hline Limited intra family relationships & 3 & Noticing the effects of anger on family & 5 \\
\hline Noticing intense family stress & 1 & Inability to speak when angry & 2 \\
\hline Spouse related & & Inability to cope with tension & 2 \\
\hline Hiding problems from one's spouse & 8 & Experiencing much conflict & 1 \\
\hline Seeing the effects of spousal problems & 5 & Communication/Relationship & \\
\hline Noticeable lack of cooperation from one's & 1 & Effective Listening & 3 \\
\hline spouse & & Insufficient family relationships & 2 \\
\hline Child related & & Familial tension & 2 \\
\hline Limited communication with one's child & 1 & Spending no time with one's family & 1 \\
\hline Taking advantage of the child's problem & & Improper communication & 1 \\
\hline Self & 1 & Noticing disconnections in the family & 1 \\
\hline Taking on excessive responsibilities & & Self & \\
\hline Setting aside no time for herself & 16 & Difficulty in expressing oneself & 1 \\
\hline Seeing the inefficacies & 9 & Facing one's problems & 1 \\
\hline Dealing with too many problems & 2 & Noticing the role of the problem & 1 \\
\hline Difficulty in expressing oneself & 2 & Needing more time & 1 \\
\hline Evading one's problems & 1 & Having limited number of people in life & 1 \\
\hline Paying no attention to others & 1 & Emotional Awareness & \\
\hline Useless coping reactions & 1 & Having difficulty in expressing oneself & 2 \\
\hline Believing that life is wasted & 1 & Offended by family & 1 \\
\hline Emotional Awareness & 1 & & \\
\hline Being without support and alone & & & \\
\hline Feeling guilty & 4 & & \\
\hline Lack of Self-confidence & 1 & & \\
\hline Being too anxious & 1 & & \\
\hline Being too hasty & 1 & & \\
\hline & 1 & & \\
\hline
\end{tabular}

As Table 4 demonstrates, this process has helped parents develop awareness of unpleasant emotional cases between themselves and all other family members. Negative aspects, as expressed by parents, included taking on too many responsibilities, setting aside no time for themselves, seeing inefficiencies, and dealing with too many problems. Reported weaknesses included relationships with the challenging root family relationships, hiding problems from the spouse, lack of cooperation from one's spouse, problems with one's child, and lack of intimate and positive familial ties.

Adolescents noticed inadequacies in anger, conflict and problem solving skills, lashing out, expressing their emotions, and the effects of their anger on their families. These inadequacies were reflected in intra family relationships and communication in a negative way.

Table 5 demonstrates findings in relation to adolescent and parental awareness of the positive and strong aspects of their lives. 
Table 5. Parental and Adolescent Awareness of Strengths

\begin{tabular}{|c|c|c|c|}
\hline \multicolumn{4}{|c|}{ Awareness about Strengths and Positive Sides } \\
\hline Parental views & $\mathbf{f}$ & Adolescent Views & $\mathbf{f}$ \\
\hline Strengths & & Strengths & \\
\hline Related to self & & Communication and Relationships & \\
\hline Knowing that they are not alone & 4 & Understanding people & 3 \\
\hline Knowing themselves better & 3 & Importance of intra family communication & 3 \\
\hline Seeing strengths & 3 & Seeing distances in the family & 2 \\
\hline Noticing parental attitudes & 2 & Communicating more openly & 2 \\
\hline Seeing that they need help & 2 & Results of ineffective listening & 1 \\
\hline Advantages of behaving calmly & 2 & Importance of listening skills & 1 \\
\hline Noticing the source of the problem & 2 & Expressing oneself & 1 \\
\hline Awareness of being a good mother & 1 & Importance of kindness & 1 \\
\hline Understanding the importance of parent & 1 & Apologizing & 1 \\
\hline consistency & & Getting along with the family & 1 \\
\hline Accepting one's problems & 1 & Anger Management and Problem Solving & \\
\hline Need for showing effort for oneself & 1 & Being able to solve conflicts & 1 \\
\hline Importance of decreasing tension & 1 & Decrease in the tone of voice & 1 \\
\hline Learning from others & & Being able to problem solve & 1 \\
\hline Acknowledging that others also have & 12 & Related to self & \\
\hline problems & & Acknowledging that the training could be & 8 \\
\hline Seeing the advantages of the group & 6 & beneficial & \\
\hline Positive effects of sharing & 3 & Noticing the need to struggle & 1 \\
\hline Advantage of two programs & 3 & Needing more friends & 2 \\
\hline Seeing different life styles & 1 & Learning new things & 1 \\
\hline Seeing other problems & 1 & Noticing that one is not alone & 1 \\
\hline Having various experiences & 1 & Emotional Awareness & \\
\hline Advantages of having a support system & 1 & Noticing emotions & 2 \\
\hline Learning from one other & 1 & Increase in self-confidence & 2 \\
\hline & & Being able to be calm down & 2 \\
\hline & & Effectiveness of relaxation & 1 \\
\hline & & Realizing that one is valued & 1 \\
\hline & & Being comfortable with the group & 1 \\
\hline & & Learning from others/Sharing & \\
\hline & & Seeing the problems of others & 5 \\
\hline & & Seeing different sides of people & 3 \\
\hline & & Meeting new people & 2 \\
\hline & & Learning from other friends & 1 \\
\hline
\end{tabular}

At the culmination of the programs, parents reported that they had gained awareness of themselves and learned from others. They reported that the group activity had positive aspects, including seeing that they were not alone, knowing themselves better, noticing strengths, noticing attitudes as parents, acknowledging that others could also have the same problem, and noticing advantages of the group.

Adolescents reported that they developed increased awareness about such issues as improvement in themselves and family communication and relationships, understanding each other, noticing the importance of intra family relationships, seeing that others could also have problems, knowing people with their different sides, communicating more openly, increasing pleasant emotions, learning from others, and sharing.

The following excerpts are participant statements on their strengths and weaknesses:

"I used to feel sorry for everything before. I used to occupy myself with sorrowful thoughts. I used to worry. I realized that I have been worn out. I was feeling really bad, even my participation was like a miracle. I used to burn myself out. I realized that I had the power to stand up for my rights" (P-4).

"First of all, I realized that I never set aside time for myself. There are sick people in my family, I have to take care of them. Thus, I ignored myself” (P-9).

"I have realized that I am actually a calm person, and I can be that way if I choose to. I realized that one should work hard in order to prevent fights. I can now hold myself back. I do not get angry quickly. Most importantly, I have realized that everybody has problems. I mean, it is not only me. Everybody has a different story” (A-2).

"I realized that I myself was the source of my anger. I could not express my emotions clearly, and I could not speak when I was angry. I realized that it was not only me; others also experience these kinds of problems. I realized that I was not alone and could actually settle down and solve this in some way (A-9).

Table 6 presents parental and adolescent perspectives on the difficulties they experienced in the process. 
Table 6. Perspectives on the difficulties experienced in the process

\begin{tabular}{|c|c|c|c|}
\hline \multicolumn{4}{|c|}{ Difficulties Experienced in the Process } \\
\hline Parent Views & $\mathbf{f}$ & Adolescent Views & $\mathbf{f}$ \\
\hline Related to self & & Related to self & \\
\hline Having difficulty in expressing & 10 & Having difficulty in expressing themselves & 14 \\
\hline themselves & & Being misunderstood & 2 \\
\hline Inability to use the support system & 4 & Knowing/socializing with new people & 2 \\
\hline Being criticized & 3 & Difficulty in eye contact & 1 \\
\hline Dread & 2 & Facing with the problem & 1 \\
\hline Concern for privacy & 2 & Having intra family problems & 1 \\
\hline Difficulty of being determined & 1 & Emotions & \\
\hline Difficulty of communicating with the & 1 & Dread & 6 \\
\hline child & & Embarrassment & 2 \\
\hline Related to spouses and children & & Being excited & 1 \\
\hline Other children's care & 5 & Time & \\
\hline Lack of spouse cooperation & 2 & Time Problem & 2 \\
\hline Not calming down the spouse & 2 & Related to the activities & \\
\hline Transportation / Time & & Anger management & 3 \\
\hline Transportation Difficulty & 5 & Practicing relaxation & 2 \\
\hline Sparing time & 3 & Guided Dream Technique & 1 \\
\hline Problem with the workplace & 2 & Difficulty in conflict resolution & 1 \\
\hline No difficulties & 2 & Difficulty in empathizing & 1 \\
\hline Related to programs and activities & & Group Nature and Rules & \\
\hline Homework & 1 & Concerns about privacy & 3 \\
\hline Not understanding some of & 1 & Crowd & 1 \\
\hline information & & Not obeying group rules & 1 \\
\hline Difficulty in practicing relaxation & 1 & & \\
\hline
\end{tabular}

An analysis of Table 6 indicates that parents experienced difficulties mainly within themselves, spouses and children, and with the program transportation and the timing of programs and activities. They also reported difficulties with issues such as expressing themselves, not being able to use the support system effectively, care and needs of other children in the process, lack of spousal cooperation of the spouse, and adjusting the timing of the program. Adolescents experienced negative emotions such as difficulties in expressing their thoughts and feelings, worries about being misunderstood, dread, embarrassment, group structure, breaking rules, adjusting the timing of the program, large groups; and had difficulties in benefitting from some activities such as applying anger management and relaxation exercises. Two parents had no difficulties with the process.

The following excerpts demonstrates some difficulties in the process reported by the participants:

"I brought my young daughter with me, which was hard. It took 40 minutes to get here. Coming here, going back, and waiting there took hours. I got anxious when my little girl made noise, for I was worried that she would disturb others. I had doubts about being here with a little girl" (P-12).

"The most difficult part was not being able to express myself in that environment. The group was very crowded. Everybody was there due to their problems. I had difficulty in expressing myself. I accept that we need to express ourselves" (P-6).

"I had difficulties in understanding my emotions and expressing them. I cannot express my emotions to other people, including my parents. Well, it is the same for them as well, this is how it is. I actually could not express myself. I had difficulty doing so, I did not want them to know that much about me" (P-4).

"I experienced difficulties in expressing myself. I am so shy. I cannot socialize easily in these kinds of environments. However, after this meeting I became more sociable after a while". (A-6).

Table 7 presents the strengths of the program provided to adolescents and parents. 
Table 7. Adolescent and Parental Views on the Strengths of the Programs

\begin{tabular}{|c|c|c|c|}
\hline \multicolumn{4}{|c|}{ Strengths of the Program } \\
\hline Parental views & $\mathbf{f}$ & Adolescent Views & $\mathbf{f}$ \\
\hline Activities & & Activities & \\
\hline Prioritizing problems & 5 & Anger Management & 8 \\
\hline Relaxation exercises & 5 & Fun nature of the ice-breaking activities & 5 \\
\hline Guided Dream technique & 5 & Relaxation exercises & \\
\hline Support System & 3 & Conflict Resolution skills & 3 \\
\hline Sit-in & 3 & Guided Dream Technique & 3 \\
\hline Family constellation & 2 & Problem Solving & 2 \\
\hline Announcement technique & 1 & Emotions & 1 \\
\hline Understanding the source of the problem & 1 & Increased calm & \\
\hline Not avoiding the problems & 1 & Feeling comfortable & 4 \\
\hline Opposing the tension increase & 1 & Feeling valued & 2 \\
\hline Problem solving methods & 1 & Communication & 1 \\
\hline Effect on/Contribution to the Family & & Expressing oneself & \\
\hline Contribution to the family & 7 & Effective listening skills & 6 \\
\hline Emotions & & Increased friendship & 2 \\
\hline Self-confidence & 3 & Empathy skills & 1 \\
\hline Increased calm & 2 & Family Relationships & \\
\hline Of the self & & Increase in intra family interaction & 9 \\
\hline Meeting new friends & 4 & Increased calm within the family & 1 \\
\hline Setting aside time for oneself & 3 & & \\
\hline Expressing oneself & 4 & & \\
\hline Applying new approaches & 1 & & \\
\hline Increase in parental presence & 1 & & \\
\hline Being with others & 1 & & \\
\hline Increase in spousal interaction & 1 & & \\
\hline Approach to the problem & & & \\
\hline Refraining from blaming or judging & 2 & & \\
\hline Being able to help others & 1 & & \\
\hline Discussing freely & 1 & & \\
\hline Articulating the problem & 1 & & \\
\hline
\end{tabular}

Table 7 demonstrates findings in relation to the strengths of the program provided to the participants. According to parents, the program had strengths such as contributing positively to themselves and to the family, prioritization of the problems, increased relaxation skills, gaining a support system, and experiencing positive emotions; meeting new people personally, setting aside time for themselves, working with new friends, and the opportunity to express themselves. As for adolescents, they mentioned that program strengths included anger management and conflict resolution, increased relaxation skills, enjoyable warm up activities, communication skills, effective listening skills, experiencing positive emotions, and improvement in familial relationships.

The following are sample statements on the adolescent and parent program strengths:

"Those little group works were good. We learned from each other because there were some people who were older or younger than us. It is not about age; maybe their education, conditions, and experiences are different" (P-4).

"I was impressed by the Family Constellation a lot. I saw distance in the family. I noticed that I had no supports. In that crowded group I had had only one supporter, my mother, and she is not alive anymore. When I went home after the training, I cried all night $(P-10)$.

"Family interaction was very important, because I did not have good relationship with my family. I benefitted from Family Constellation because I was affected mostly by that; but I felt that I did not have many people around me. I realized that I was offended." (A-4).

"I think the best thing was the Family Constellation. When my friend participated in it, I tried to visualize mine in my mind. My parents are always with me. No matter what I do, or what I've done, my parents have always been with me. I realized this and it touched me. Knowing this affected me and made me happy. I benefitted mostly from the family interaction" (A-6).

Table 8 demonstrates participant views on the program's weaknesses. 
Table 8. Adolescent and Parental Views on the Program's Weaknesses

\begin{tabular}{|c|c|c|c|}
\hline \multicolumn{4}{|c|}{ Program Weaknesses } \\
\hline Parent Views & f & Adolescent Views & f \\
\hline Group climate, time and conditions & & Group climate, time and conditions & \\
\hline Privacy concerns & 2 & Breaking of group rules & 11 \\
\hline Members who do not speak & 2 & Crowded groups & 6 \\
\hline Occasional tension & 1 & Limited opportunities for expressing oneself & 3 \\
\hline Crowded groups & 1 & Time constraints & 3 \\
\hline Insincerity & 1 & Participants & \\
\hline Time constraints & 1 & Absence of the other parent & 6 \\
\hline Participants & & Inability to understand/apply & \\
\hline Absence of spouses & 13 & activities & \\
\hline Lack of contributions to spousal relationships & 6 & Relaxation skills & 5 \\
\hline Lack of cooperation with the spouse & 3 & Guided Dream technique & 1 \\
\hline Inability to understand/apply the activities & & Effective listening skills & 3 \\
\hline Inability to apply sit-in & 2 & Intra family interaction activity & 3 \\
\hline Inability to understand the videos & 2 & Problem Solving Skills Education for & 2 \\
\hline Inability to apply relaxation skills & 1 & families & \\
\hline Inability to prioritize problems & 1 & No change in communication with one's & 2 \\
\hline Difficulty in practicing what has been learned & 1 & father & \\
\hline Uninteresting topics & 1 & Conflict Resolution & 2 \\
\hline No weaknesses & 1 & No weaknesses & 3 \\
\hline
\end{tabular}

An analysis of these concepts indicate that parents mentioned inadequacies such as: lack of spousal participation; lack of program contributions to spousal relationships and lack of cooperation; inability to understand or apply the activities; privacy concerns about the group environment; time and conditions; members who do not contribute to discussions; time constraints; crowded groups; and an inability to create a friendly atmosphere.

Adolescents indicated the following program weaknesses: lack of opportunity to express oneself; not fully obeying group rules in the process; crowded groups; other parents' lack of participation; inability to benefit from or apply some activities; inability to fully apply relaxation skills; conflict resolution; intra family communication; effective listening skills; and insufficient time allocated to conflict and problem solving with parents. Despite being few in number, some participants stated that the program did not have any faults.

The following are sample participant statements on the problematic aspects of the program.

"I did not benefit from the support system much because it is not something we need in our family. Our spouses did not participate. For me, this was the only fault. No matter how much training I receive, I might not achieve something if my husband does not support it" (P-9).

"Only I had the training. It would have been more beneficial if all family members had been involved. If all spouses and children had been involved, more peace would be maintained in the family; at least in my family. We could have been a model for other people; we could have cooperated. (P-7).

"It was time allocation really, if it had been two or three hours instead of one to one-and-a-half hours, people could have expressed themselves more. Each week centered on a different topic. Everybody had problems, no one was there without any problems and therefore more time was needed" (A-5).

"I wish we could have worked on more questions that would help us communicate better or play more games. I cannot express myself, so some games and role-playing activities could have been included" (A-7).

Table 9 presents the suggestions of adolescents and parents regarding the program applied. 
Table 9. Suggestions of Adolescents and Parents Regarding the Program

\begin{tabular}{|c|c|c|c|}
\hline \multicolumn{4}{|c|}{ Suggestions about the program } \\
\hline Parental Views & $\mathbf{f}$ & Adolescent Views & $\mathbf{f}$ \\
\hline Participants & & Participants & \\
\hline Spouses should participate together & 7 & Parents should receive training together & 9 \\
\hline Fathers should participate & 6 & Full family participation required & 4 \\
\hline Children should be involved & 3 & Only interested people should participate & 1 \\
\hline Full family participation required & 3 & Group climate, time and rules & \\
\hline Only interested people should participate & 1 & Should be held during weekends & 8 \\
\hline Group climate, time and rules & & There should be fewer participants & 8 \\
\hline Should be held during weekends & 5 & Participants should obey the rules & 5 \\
\hline Should be in the evenings & 1 & Should be held during weekends & 5 \\
\hline Should be constructive & 1 & More flexible hours & 2 \\
\hline Everybody should be respectful & 1 & Should be held in an open area & 1 \\
\hline What is told should be applied & 1 & More time should be allocated & 1 \\
\hline \multirow[t]{10}{*}{ There should be fewer participants } & 1 & Should be conducted in a quieter setting & 1 \\
\hline & & $\begin{array}{l}\text { Group members should not know each other } \\
\text { Content }\end{array}$ & 1 \\
\hline & & There should be individual counselors & 9 \\
\hline & & $\begin{array}{l}\text { Family constellation should be conducted } \\
\text { with everyone }\end{array}$ & 2 \\
\hline & & Families should be given more information & 2 \\
\hline & & More games & 1 \\
\hline & & More role-playing activities & 1 \\
\hline & & Increased conflict resolution skills & 1 \\
\hline & & Increased listening skills & 1 \\
\hline & & Participants' desires should be considered & 1 \\
\hline
\end{tabular}

An analysis of Table 9 demonstrates that parents made program suggestions including: enhancing couple participation;, full family involvement in the program; involving people who are interested; being respectful to the group environment; program timing and rules; applying what was taught; and conducting trainings in the evenings or during the weekends so that more people can participate.

Adolescents had various suggestions that included: involving both parents and all family members in trainings; flexible group timings (e.g., during the weekends or evenings); and groups with fewer people. As for content, they suggested enabling individual help, applying Family Constellation to all participants, giving families more information, and increasing games and role-playing activities.

The following excerpts are sample participant suggestions regarding the program:

"It would have been much better if my husband and children had been here with me. I wish it had been so. Yes, it would have been more beneficial if fathers and children had been together. This training should be given to parents and children together $(P-12)$.

"Attending the program during weekdays could be more convenient for me. I have a son who attends secondary school. I always think of him. I had difficulty getting here" (P-6).

"It would be better if the program were held during weekends and conducted with the participation of both mothers and fathers. If my dad had been here, for example, I would now have no problems with him" (A-1).

"It is more logical to have smaller groups, with the participation of those who would attend in earnest. I think uninterested people affect the group in a negative way. Groups should be smaller" (P-6).

\section{Discussion}

This study investigated the views of parents who participated in the 'Non-Violent Resistance" program with regard to their training. Interviews conducted with parents about the emotions they experienced during the process revealed that they experienced mainly positive/pleasant emotions such as: calm; relief; happiness; feeling valued; feeling support from non-family members; and having the freedom to express oneself.

Parents generally reported that they gained new skills with the program. According to them, they improved largely in areas such as intra family interaction, conflict resolution, and anger management and relaxation skills. The Guided Dream technique and relaxation skills are the two items in particular that made great contributions to themselves and other family members. Parents stated that their self-awareness and awareness of their family increased with the program. They realized that they took on many familial responsibilities, that they could not set aside time for themselves, that everybody has different problems, that they were not alone, and that there was distance in family interactions. Parents also thought that the psycho-education program provided to their children had very positive effects on them, increasing their children's level of 
calm, intra family communication, anger management skills, while decreasing reactional behaviors.

As for the positive effects of the program on their families, the parents stated that relationships in their family increased, particularly with their children; family members became closer to one another, there was an increase in communication, and the home atmosphere began to relax. On the other hand, the parallel programs enabled parents and their children to set positive communication, feel less helpless and more adequate as parents, and feel like they did something special for themselves. The participants stated that they had difficulties primarily in self-expression, and they also had difficulties in their children's care and use of support system, the program did not have much contribution to spouse relationships, and was also inadequate with issues such as absence or lack of spousal contribution. They suggested that spouses should be involved in the trainings, fathers should be involved, children should also have training in the same environment, and that participation could be increased by holding trainings during weekends or evenings.

An analysis of experiential studies on parental skills in literature indicates that these studies are mainly quantitative in nature in Turkey and throughout the world. Although they are very few in number, there are some qualitative studies that include participant views as well. Yeşilleten (2001) administered trainings for mothers and found that parents' self-confidence increased after the programs, they began to communicate with their children more effectively, they learned to cope with problems better, children began to share their problems and emotions with their mothers more frequently, and children's decision making and problem solving skills increased.

An analysis of some of the similar experiential studies conducted in Turkey indicates that parents displayed differences in their relationships with their children, their problem solving skills increased, this effect caused positive changes in parental life and various aspects of parenting, negative parent attitudes decreased, self-respect and satisfaction levels increased, and parental skills toward establishing close relationships with their children increased (Özdemir, 1991; Pehlivan, 2008; Kocayürek and Sümer, 2009). Results of this study are generally parallel to the qualitative and quantitative findings of the studies conducted before. Experiential studies conducted in other countries report that in a similar vein, positive parenting practices increased after the program's completion; stress, anxiety and depression levels of parents decreased; there was a decrease in conflict between parents and children and between parents; dysfunctional parenting practices decreased; parents' anger levels decreased and self-confidence levels increased; and problematic behaviors in their children decreased (Sanders, 2000; Sanders, Cann, Markie-Dadds, 2003; Stallman and Ralph, 2007; Sanders and Ralph; 2009).

Adolescent opinions on the process indicate that the experiential group reported to have benefited from the "Coping with Violence and Aggression" program. Interviews conducted with students at the end of the process indicated that they experienced mainly positive or pleasant emotions such as calming, relief, self-confidence, worthiness, happiness, and joy. The students also stated that they sometimes experienced negative or unpleasant feelings such as anxiousness, uneasiness, and difficulty in expressing themselves. The adolescents also stated that they gained new skills thanks to the program, and that this circumstance contributed to their relationships with friends and family members. They stated that they made self-improvements in communication skills, conflict resolution, anger management, and relaxation skills. They stated in particular that their parents' having received education also contributed positively to their approach styles and trust levels.

Additionally, adolescents learned the importance of meeting and socializing with new friends and communication, the effects of lash out when angry and intra family interactions on individuals and family members, and insufficient communication with their family. As for positive effects of the program on their familial relationships, the adolescents stated that their intra family relationships increased, family members became closer to one another, and there was a calmer family atmosphere. They also stated that they sometimes had difficulty in expressing themselves, experienced anxiety regarding privacy, and had difficulty in applying the relaxation exercises. The participants indicated that some program weaknesses included the breaking of rules from time to time, crowded groups, and involving only one parent in the program. Some suggestions included having the opportunity to receive individual help, involving both parents in the trainings, obeying the rules, and forming groups with fewer participants.

Studies that focus on aggressive behaviors and family relationships in adolescents indicate that the studies that investigate participant opinions on the effects of these experiential programs are quite limited in number. An analysis of studies on violence and aggression in adolescents in Turkey and in the world indicates that the education programs decreased adolescents' negative attitudes and behaviors such as anger, violence, and aggression, while increasing communication, problem solving, negotiation and mediation, anger management, conflict resolution, healthy family functions, and social skills (Siyez and Tan-Tuna, 2014; Bacığlu, 2014; Yavuzer, Karataş and Gündoğdu, 2013; Bedel and Ar1, 2011; Yavuzer and Üre, 2010; Shechtman and Ifargan, 2009; Gültekin, 2008; Şevkin, 2008; Ando, Asakura, Ando and Simons-Morton, 2007; Akdeniz, 2007; Tekinsav-Sütçü, 2006; Fong, 2006; Uysal, 2006; Şahin, 2006; Karataş, 2005; Duran and Eldeleklioğlu, 2005; Herrmann and McWhirter, 2003; Aber, Jones and Brown, 2003; Sharp, 2003).

In sum, the results of this study, which is based on family interactions and functions and which aims to decrease 
adolescents' aggressive behaviors, demonstrate parallelism with many studies in Turkey and across the globe. Experiential studies conducted in Turkey focused mainly on children and adolescents, or parents; and the number of studies on violence and aggression that investigated parents and their children together are quite limited. This program, which is based on the notion that the family is handled as a unit and that the interaction formed in this system could affect attitudes and behaviors of all family members, thereby contributing to increased parent and adolescent communication in Turkish families. Application of the program in tandem with school psychological counselors at schools could help parents who feel inadequate and helpless about coping with their children's violent and aggressive behaviors. Involving not only adolescents and parents experiencing problems but also school administrators and teachers in the program in a framework of a holistic approach could be more beneficial in coping with the multidimensional issues of violence and aggression. Generalizations of the findings of this study are limited with the nature of the activities in the program, its duration, and the effectiveness of its researchers' practices. Results of this experiential study can be generalized only in the student and parent groups with similar features.

\section{Appendix}

This article is part of a doctoral thesis. It was presented as a summary oral presentation at the Conference of the Turkish Psychological Counselling and Guidance Association on December 1-3, 2016. I would like to thank the Çukurova University Scientific Research Fund for their support.

\section{References}

Aber, J. L., Brown, J. L., \& Jones, S. M. (2003). Developmental trajectories toward violence in middle childhood: Course, demographic differences, and response to school-based intervention. Developmental Psychology, 39(2), 324-348. https://doi.org/10.1037/0012-1649.39.2.324

Akdeniz, M. (2007). The Effect Of Anger Control Skills On High School Students' Anger Control Training. (Unpublished Master's Thesis). Çukurova University, Adana, Turkey.

Ando, M., Asakura, T., Ando, S., \& Simons-Morton, B. (2007). A psychoeducational program to prevent aggressive behavior among Japanese early adolescents. Health Education and Behavior, 34, 765-776. https://doi.org/10.1177/1090198106291965

Arkan, B., \& Üstün, B. (2009). Parent Education Programs as a Psychiatric Approach to Children with Conduct Disorder: An Evaluation through Two Samples. Current Approaches In Psychiatry, 1, 155-174.

Bacioğlu (2014) Effectiveness of Prevention Programs Reducing Violence and Aggression: A Meta-Analysis Study. Turkish Psychological Counseling and Guidance Journal, 5(42), 294-304.

Bedel, A., \& Ar1, R. (2011). Interpersonal Problem Solving Skills Training's Effect on the Adolescents' Living in Orpanhages Constructive Problem-Solving and the Level of Trait Anger. Pegem Journal of Education and Instruction, 1(4), 1-10.

Bugental, D. B., Blue, J., \& Cruzcosa, M. (1989). Perceived control over caregiving outcomes: Implications for child abuse. Developmental Psychology, 25, 532-539. https://doi.org/10.1037/0012-1649.25.4.532

Büyüköztürk, Ş. (2007). Experimental Patterns Pre-Posttest Control Group Pattern and Data Analysis (2nd edition). Ankara: Pegem A Publishing.

Cerit, T. (2007) Examination of perception of family relationships of Adolescents by some variables. (Unpublished Master's Thesis). Gazi University, Ankara.

Donat-Bacıŏlu, S., \& Özben, Ş. (2011). The Effect of Vıolence And Aggression In Chıldren and Adolescent Prevention Programme on Decreasing Adolescent Aggression. Trakya University Journal of Educational Faculty, 1(2), 137-155.

Duran, Ö., \& Eldeleklioğlu, J. (2005). Investigation of The Efficiency of The Anger Control Programme Over 15-18 Years Old Adolescents. Gazi University Journal of Gazi Educational Faculty (GUJGEF), 25(3), 267-280.

Elizabeth, D., \& Elisabeth, H. (2010). Non-violent resistance programme: Guidelines for parents, care staff and volunteers working with adolescents with violent behaviours. Publisher: Pavilion Publishing (Brighton) Ltd.

Fong, J. (2006). Psychodrama as a preventive measure: Teenage girls confronting violence. Journal of Group Psychotherapy, Psychodrama and Sociometry, 59(3), 99-108. https://doi.org/10.3200/JGPP.59.3.99-108

Freedman, J. L., Sears, D. O., \& Carlsmith, J. M. (2003). Social Psycholgy. (trans. by. A. Dönmez), Ankara: Imge Bookstore.

Furman, R., Langer, C. L., \& Taylor, D. B. (2010). Analyzing narratives through poetic forms and structures in gerontology: Applying new tools in qualitative research. Journal of Poetry Therapy, 23(2), 61-71. 
https://doi.org/10.1080/08893675.2010.482809

Gültekin, F. (2008). The Effect of Aggression and Anger Reduce Program on Level of Aggression and Anger of Middle School Students, (Unpublished doctoral dissertation). Hacettepe University, Ankara.

Herrmann, D. S., \& McWhirter, J. J. (2003). Anger and aggression management in young adolescents: an experimental validation of the SCARE program. Education And Treatment of Children, 26(3), 273-302.

Karataş, B. Z. (2005). Relatıonshıp Of Parent's Aggressıon And Student's Aggression. Journal of Contemporary Education, 30(317), 30-39.

Karataş, Z., \& Gökçakan, Z. (2009). The Effect of Group-Based Psychodrama Therapy on Decreasing the Level of Aggression in Adolescents. Turkish Journal of Psychiatry, 20(4), 357-366.

Kaymak-Özmen, S. (2013). The Effect of Parent Training Program on Behavioral Problems of Children and the Depression Levels of Parents. Education and Science, 38(167), 98-113.

Kocayürek, E., \& Sümer, H. Z. (2009). The Effects of Father Involvement Training On Family Functioning and Adolescents' Peer Relation. Journal Of Theory And Practice In Education, 5(1), 3-17.

Lavi-Levavi, I., Shachar, I., \& Omer, H. (2013). Training in Nonviolent Resistance for Parents of Violent Children: Differences Between Fathers and Mothers. Journal of Systemic Therapies, 32(4), 79-93. https://doi.org/10.1521/jsyt.2013.32.4.79

McCart, M. R., Priester, P., Davies, W. H., \& Azen, R. (2006). Differential effectiveness of behavioral parent-training and cognitive-behavioral therapy for antisocial youth: A meta-analysis, Journal of Abnormal Child Psychology, 34(4), 525-541. https://doi.org/10.1007/s10802-006-9031-1

Minuchin, S. (1974). Families and family therapy. Cambridge MA: Harvard University Press.

Omer, H. (2001). Helping parents deal with children's acute disciplinary problems without escalation: The principle of non-violent resistance. Family Process, 40, 53-66. https://doi.org/10.1111/j.1545-5300.2001.4010100053.x

Omer, H. (2004). Nonviolent resistance: A new approach to violent and self-destructive children. Cambridge: Cambridge University Press.

Omer, H. (2011). The new authority: Family, school and community. New York: Cambridge University Press.

Omer, H., \& Schlippe, A. V. (2002). Authority without violence: Coaching the parents of children with behavior problems. Goettingen: Vandenhoeck \& Ruprecht (Almanca).

Omer, H., \& Schlippe, A. V. (2004). Authority through relating: The practice of non-violent resistance in child-rearing. Goettingen: Vandenhoeck \& Ruprecht (Almanca).

Omer, H., Shor-Sapir, I., \& Weinblatt, U. (2006). Non-violent resistance and violence against siblings. In C. Tsirigotis,

Omer, H., Steinmetz, S. G., Carthy, T., \& Schlippe, A. V. (2013). The Anchoring Function: Parental Authority and the Parent-Child Bond. Family Process, 52, 193-256. https://doi.org/10.1111/famp.12019

Özdemir, A. (1991). A Study On The Effectiveness Of Mother Training On Mothers, Bogazici University Social Sciences Institute (Unpublished master thesis). Istanbul.

Pehlivan, H. (2008). Assessment of the Effectiveness of the Maternal Education Program. Family and Society Education Culture And Research Journal,4 (15), 55-66.

Polowczyk, M., Trautmann ,V. P., Dinter, J. M., Gerhold, M., Laucht, M., Schmidt, M. H., et al. (2000). Auffällige Mutter-Kind-Interaktion im Vorschulalter bei Kindern mit hyperkinetischen und Sozialverhaltensauffälligkeiten. Zeitschrift fuer Klinische Psychologie und Psychotherapie: Forschung und Praxis, 29(4), 293-304. https://doi.org/10.1026//0084-5345.29.4.293

Şahin, \& Kalburan, (2009). Parent Education Programs and Their Effectiveness: What Type of Programs are Implemented in the World? Pamukkale University Journal of Education, 1(1), 88.

Şahin, H. (2006). The Effectiveness of the Anger Management Program of Decreasing Aggressive Behaviours. Turkish Psychological Counseling and Guidance Journal, 3(26), 47-61.

Sanders, M. R. (2000). Triple P - Positive Parenting Program: A population approach to promoting competent parenting. Australian E-Journal For The Advancement of Mental Health, 2(3), 1-17.

Sanders, M. R., \& Ralph, A. (2009). Facilitator's manual for Group Teen Triple (P. Milton), QLD, Australia: Triple P International Publishing.

Sanders, M. R., Cann, W., \& Markie-Dadds, C. (2003). The Triple P-Positive Parenting Programme: A Universal. 
Population-Level Approach to the Prevention of Child Abuse. Child Abuse Review; 12, 155-171. https://doi.org/10.1002/car.798

Sanders, M. R., Ralph, A., Thompson, R., Sofronoff, K., Gardiner, P., Bidwell, K., \& Dwyer, S. (2005). Every Family: A Public Health Approach To Promoting Children's Wellbeing. Brisbane, Australia: The University of Queensland.

Scheckner, S., Rollin, S. A. , Kaiser-Ulrey, C., \& Wagner, R. (2002). A meta-analysis of the effectiveness of current interventions. Journal of School Violence, 1(2), 5-32. https://doi.org/10.1300/J202v01n02_02

Schlippe, A. V. (2006). From family therapy to systemic parental coaching. (Ed. C. Tsirigotis, A. V. Schlippe ve J. Schweitzer-Rothers), içinde, Coaching For Parents: Mothers, Fathers and Their "Job”, (pp. 44-67), Heidelberg: Carl Auer (Germany).

Şevkin, B. (2008). Searching The Effects Of Conflict Resolution Styles And Agression Tendency On 4th And 5th Grade Students In Primary School Of "Negotiation (Problem Solving) And Mediation" Education Programme. (Unpublished master's thesis). Dokuz Eylül University Educational Sciences Institute, Izmir.

Sharp, S. R. (2003). Effectiveness of an anger management training program based on rational emotive behavior theory (rebt) for Middle School students with behavior problems. (Unpublished doctoral dissertation). The University of Tennessee.

Shechtman, Z., \& Ifargan, M. (2009). School-based integrated and segregated interventions to reduce aggression. Aggressive Behavior, 35, 342-356. https://doi.org/10.1002/ab.20311

Siyez, \& Tan-Tuna (2014). Effect of Solution Focused Programme on Adolescents' Anger Control and Communication Skills. Turkish Psychological Counseling and Guidance Journal, 5(41), 11-22.

Stallman, H. M., \& Ralph, A. (2007). Reducing risk factors for adolescent behavioural and emotional problems: A pilot randomised controlled trial of a self-administered parenting intervention. Australian e-Journal for the Advancement of Mental Health, 6(2), 1-13. https://doi.org/10.5172/jamh.6.2.125

Sukhodolsky, D. G., Kassinove, H., \& Gorman, B. S. (2004). Cognitive-behavioral therapy for anger in children and adolescents: A Meta Analysis, Aggression and Violent Behavior, 9(3), 247-269. https://doi.org/10.1016/j.avb.2003.08.005

Tekinsav-Sütçü, G. S. (2006). Effectiveness of a Cognitive Behavioral Group Therapy Program for Reducing Anger and Aggression in Adolescents. (Unpublished doctoral dissertation). Ege University, Izmir.

Uysal, Z. (2006). The Effects of Conflict Resolution Training Programme on Ninth Grade Students Conflict Resolution Skllls. (Unpublished master's thesis). Cukurova University, Adana.

Weinblatt U., \& Ömer, H. (2008) Non-violent resistance: A treatment for parents of children with acute behavior problems. Journal of Marital and Family Therapy, 34(1), 75-92. https://doi.org/10.1111/j.1752-0606.2008.00054.x

Wilson, D. B., Gottfredson, D. C., \& Najaka, S. S. (2001). School based prevention of problem behaviors: A meta-analysis. Journal of Quantitative Criminology, 17, 247-272. https://doi.org/10.1023/A:1011050217296

Wilson, S. J., \& Mark W. L. (2005). Revised report for the national institute of justice school violence prevention research planning. Lipsey Center for Evaluation Research and Methodology Institute for Public Policy Studies. Vanderbilt University.

Wilson, S. J., \& Mark, W. L. (2007). Update of a meta-analysis of school-based intervention programs. American Journal of Preventive Medicine, 33(2),130-143. https://doi.org/10.1016/j.amepre.2007.04.011

Yavuzer, Y., \& Üre, Ö. (2010). The Effect of Psycho-Education Program Towards Preventing Aggression on Decreasing Aggressiveness of High School Students. Selcuk University Journal of Institute of Social Sciences, 24, 389-405.

Yavuzer, Y., Karataş, Z., \& Gündoğdu, R. (2013). An Investıgatıon of Conflıct Resolutıon Behavıurs: A Quantıtatıve And Qualitatıve Study. Hacettepe University Journal of Education, 28(1), 428-440.

Yeşilleten, A. (2001). Parent education programs in programs in selected private psychological counseling centers in İstanbul. Masters of Arts Boğaziçi University Institute of Social Sciences.

Yıldırım, A., \& Şimşek H. (2006). Qualitative Research Methods. Ankara: Seckin Publishing.

\section{Copyrights}

Copyright for this article is retained by the author(s), with first publication rights granted to the journal.

This is an open-access article distributed under the terms and conditions of the Creative Commons Attribution license which permits unrestricted use, distribution, and reproduction in any medium, provided the original work is properly cited. 